\title{
Expansão Agrícola no Brasil e a Participação da Soja: 20 anos $^{1}$
}

\author{
Rogério Edivaldo Freitas² e Marco Aurélio Alves de Mendonça ${ }^{3}$
}

Resumo: Este artigo teve por objetivo detectar o sentido de expansão da área de produção da agricultura brasileira no período de 1994 a 2013, bem como a participação da cultura da soja neste fenômeno. Empregaram-se dados da pesquisa de Produção Agrícola Municipal (PAM), do Instituto Brasileiro de Geografia e Estatística (IBGE), quanto às mesorregiões brasileiras. Indicadores de crescimento e procedimentos de análise de grupamentos foram utilizados para identificar semelhanças em aumento de área agrícola entre as mesorregiões brasileiras. Ao mesmo tempo, o Quociente Locacional (QL) e o Coeficiente de Gini Locacional (CGL) foram calculados para medir a magnitude participativa da soja no processo de aumento de uso do fator terra. Os resultados evidenciam a dinâmica de expansão de área agrícola pela rota Centro Noroeste do País, com projeções na direção dos trechos ocidentais e sul da região Norte. Quanto à soja, houve a proeminência da leguminosa na rota de expansão do uso do solo para fins agrícolas.

Palavras-chaves: Agricultura; Soja; CGL; Análise de grupamentos; Mesorregiões.

Abstract: The article tried to map the inherent differences stemming from the growth in production area for Brazilian agriculture during the period 1994-2013 within the context of Brazilian mesoregions as well soybeans share in this process. The study employed data from the Brazilian Institute of Geography and Statistics. Cluster Analysis and two increasing indicators were used to identify similarities among the Brazilian agricultural mesoregions, and Locational Quotients and Gini Locational Coefficients were calculated to measure the soybean participative amount in such phenomenon. Results highlight a frontier agricultural area in the central-northwest of Brazil. Concerning the soybean results expose its prominent share in the detected growth of used area for agricultural ends.

Key-words: Agriculture; Soybean; LGC; Cluster analysis; Mesoregions.

DOI - http://dx.doi.org/10.1590/1234-56781806-94790540306 Classificação JEL: O18, Q15.

1. Data de submissão: 2 de outubro de 2015. Data de aceite: 24 de maio de 2016.

2. Instituto de Pesquisa Econômica Aplicada (Ipea), Brasília/DF, Brasil. E-mail: rogerio.freitas@ipea.gov.br

3. Instituto de Pesquisa Econômica Aplicada (Ipea), Rio de Janeiro/RJ, Brasil. E-mail: marco.mendonca@ipea.gov.br 


\section{Introdução}

O aumento da produção de alimentos é uma das principais questóes a ocupar o centro das preocupações no século XXI. As projeções da Organização das Nações Unidas (UN, 2013) sinalizam para uma população global de 9,5 bilhões de pessoas em 2050 e para aumentos na demanda mundial de alimentos, aumentos estes associados a maiores rendas per capita e à crescente taxa de urbanização em especial nos países em desenvolvimento.

Ao mesmo tempo, nações como Rússia, Estados Unidos, Argentina, Austrália, Canadá e os membros da União Europeia já não mais detêm espaço facilmente aproveitável para expansão de área agrícola em condições técnicas e/ou economicamente viáveis.

No caso brasileiro, é conhecido o processo de expansão agrícola que se originou do Sul e adentrou áreas do Cerrado. Hoje se argumenta que o fenômeno se espraia pelos estados de Maranhão, Tocantins, Piauí e Bahia, com reflexos em ocupação de área da própria região Norte do País, onde Pará, Amazonas e Tocantins têm experimentado recentemente aumento do preço de terras (GASQUES, BOTELHO e BASTOS, 2015), uma consequência da própria dinâmica de ocupação de novas áreas.

Embora haja impactos ambientais neste processo (SAUER e LEITE, 2012), particularmente no tocante à expansão da soja e aos preços e apropriação de terra por estrangeiros no Brasil, outros analistas (SPAROVEK et al., 2016) argumentam que o fenômeno da expansão de área agrícola pode contemplar uma base comum de interesses entre agricultores e conservacionistas.

Destarte, o estudo objetiva diagnosticar os núcleos de expansão de área agrícola no Brasil ao longo do intervalo de 20 anos entre 1994 e 2013. Adicionalmente, busca-se mensurar a participação do plantio de soja neste processo.

Escolheu-se aprofundar a análise com o caso da soja por ser um produto de reconhecida competitividade internacional para o Brasil (SOUZA et al., 2012) e de marcante importância nas exportações agropecuárias (ESPIRITO SANTO, LIMA e SOUZA, 2012; ALMEIDA, SELEME e NETO, 2013; FREITAS, 2014). Ademais, é fato reconhecido a grande participação do farelo de soja no arraçoamento de aves e suínos, com impactos nos preços internos de carnes e lácteos.

Isto posto, a seção 2 foi reservada à apresentação dos dados e ao detalhamento metodológico. Já os itens 3 e 4 destinam-se à discussão dos resultados e às considerações finais, respectivamente.

\section{Metodologia e fonte de dados}

O estudo utilizou dados de valor da produção (R\$) e de área de produção (ha) da Produção 
Agrícola Municipal (PAM) disponibilizados pelo Instituto Brasileiro de Geografia e Estatística (IBGE) (2015) de 1994 a 2013, em nível de mesorregiões, e obtidos junto ao Sistema IBGE de Recuperação Automática (Sidra) do mesmo órgão.

Este período contempla uma vantagem significativa que é a de englobar períodos produtivos realizados sob a égide de uma única moeda interna, o Real (R\$), fundamental para mitigar inúmeros problemas oriundos da instabilidade monetária de períodos precedentes a 1994. Quanto à opção pelas mesorregiões, representa uma alternativa de parcimônia, podendo-se aprofundar a investigação, a critério ou necessidade, para o nível de áreas geográficas mais desagregadas. ${ }^{4}$

Dois procedimentos foram empregados para medir e detectar as mesorregióes brasileiras com crescimento diferenciado em termos de expansão da área agrícola.

Em primeiro lugar, foram calculados os percentuais de média de crescimento da área agrícola para cada uma das 137 mesorregiões brasileiras. Na equação (1) mensurou-se a taxa de crescimento da área agrícola pela mesorregião $i$ no ano $t$, com base em 1994:

$$
I_{l i}=\sum_{t}^{T}\left(C_{94, t}\right) / 19 \quad t=1995, \ldots, T
$$

Como controle adicional por conta do efeito das intempéries climáticas sobre a produção agrícola e de modo a ter um indicador de curto prazo recente, desdobrou-se o indicador anterior no indicador (2), de modo a contemplar exclusivamente o quinquênio ${ }^{5}$ 2008-2013 frente ao ano-base 1994.

4. Optou-se pelas mesorregiões por se tratar de uma análise ainda agregada, objetivo do trabalho dos autores nesta etapa. Os autores reconhecem como uma limitação do estudo. Inclusive, em diversas reuniões do Levantamento Sistemático da Produção Agrícola (LSPA), que produz os dados finais da PAM, esta é uma dificuldade reconhecida em face da não existência de Censos Agropecuários em menores intervalos temporais. Todavia, a partir do presente trabalho torna-se possível realizar procedimentos mais finos.

5. O período de cinco anos foi usado em função de uma sugestão feita em seminário na Escola Superior de Agricultura "Luiz de Queiróz" (Esalq/USP) por ocasião da apresentação de versão preliminar do estudo.

$$
I_{2 i}=\sum_{t}^{T}\left(C_{94, t}\right) / 5 \quad t=2008, \ldots, 2013
$$

Para avaliar a expansão das áreas estudadas, utilizou-se a técnica estatística de análise de grupamentos. Este procedimento tem como objetivo dividir elementos da amostra em grupos de forma que os elementos pertencentes a um grupo sejam similares entre si com respeito às variáveis (características) que neles foram medidas e os elementos em grupos diferentes sejam heterogêneos com relação às características priorizadas.

Uma questão-chave refere-se ao critério a ser utilizado para se decidir em que medida dois elementos do conjunto de dados podem ser considerados semelhantes ou não. Logo, torna-se necessário empregar medidas ou variáveis que descrevam similaridade entre elementos amostrais de acordo com os atributos que neles foram mensurados.

Neste trabalho foi considerada a distância euclidiana ${ }^{6}$, que, entre dois elementos, 1 e $k$, é definida em função dos vetores de variáveis $\mathrm{X}$ associadas a cada um dos elementos, expressando-se como na equação (3):

$$
\begin{aligned}
& d\left(X_{1}, X_{k}\right)=\left[\left(X_{1}-X_{k}\right)\left(X_{1}-X_{k}\right)\right]^{1 / 2}= \\
& =\left[\sum_{i=1}^{p}\left(X_{i 1}-X_{i k}\right)^{2}\right]^{1 / 2}
\end{aligned}
$$

em que:

p: número de variáveis (características) de cada elemento;

$k$ : número de elementos.

Conforme Pereira (2001), essa análise pode ser estendida do espaço bidimensional para um espaço multidimensional para o caso de $n$ diferentes medidas (características) $X$ do objeto de estudo porque a distância entre dois pontos sempre será linear e passível de visualização num plano. Tal distância terá uma unidade de medida

6. Há vários métodos aglomerativos, tipificados de acordo com o critério usado para definir as distâncias entre grupos como o método do vizinho mais próximo, centróide etc. Aqui, utilizou-se a distância média que é consolidada na literatura de clusters. 
abstrata e, por isso, não será medida na escala de nenhuma das variáreis sob análise.

Em termos operacionais, para o caso da expansão de área agrícola nas mesorregiões brasileiras, de pronto citam-se três variáveis-chave de avaliação. Em primeiro lugar, a área plantada (ou Área Destinada à Colheita, ADC), que corresponde à intenção de colheita do produtor na hipótese virtual de nenhuma perda de área durante as operações de plantio, manejo e colheita. Em segundo lugar, o Valor Bruto da Produção (VBP), que corresponde à receita bruta da atividade em unidades monetárias, o que incentiva em maior ou menor grau a ocupação e os tratos culturais de novas áreas. E, por fim, mas não menos relevante, a Perda de área $(P)$, equivalente à expressão abaixo:

$$
P=\text { A.D.C }- \text { A.C. } \quad t=1994, \ldots, T
$$

em que:

A.D.C.: área destinada à colheita em hectares;

A.C.: área colhida em hectares.

A área destinada à colheita é representada como uma função dos preços de mercado dos produtos agrícolas, dos preços dos respectivos insumos e das condições tecnológicas de operação. Já a área colhida é uma função das mesmas variáveis da área destinada à colheita e de variáveis randômicas como incidência de pragas e condições climáticas durante as operações a campo.

Portanto, pode-se dizer que a perda de área (função da área colhida) também é uma variável randômica. Além disso, é razoável observar uma maior incidência de perda de área nas regiões de expansão agrícola recente, porque há um período necessário de adaptação dos solos ultimamente ocupados durante o incremento de uso de área.

É sabido que as variáveis climáticas, de qualidade de solo e também de manejo como controle de pragas, que não estão sob pleno controle do produtor e que afetam o nível de área colhida impactam diretamente o nível de perdas verificado no momento das safras.

O procedimento de cálculo foi dividido em duas etapas. Inicialmente, o método hierárquico aglomerativo foi utilizado na análise dos dados para tentar indicar uma quantidade de agrupamentos que melhor se adequasse ao universo das mesorregiões. ${ }^{7}$ Nele, cada elemento inicia-se representando um grupo e, a cada passo, um grupo ou elemento é ligado a outro de acordo com sua similaridade até o último passo, em que é formado um grupo único com todos os elementos que apresentem similaridade para aquela característica mensurada.

Em segundo plano, após a análise ano a ano, construiu-se uma tabela com os resultados dos testes pseudo $\mathrm{T}$ e pseudo $\mathrm{F}^{8}$ que indicam o número de agrupamentos com maior ganho de informação. Os cálculos foram realizados com a utilização das variáveis em taxas de crescimento (área), em nível (área e perda de área) e normalizadas (área, perda de área e valor bruto da produção).

Num segundo nível de abordagem metodológica foram utilizados o Quociente Locacional (QL) e o Coeficiente de Gini Locacional (CGL) com vistas a mensurar a participação do plantio de soja neste processo.

Tomando-se o caso da variável área agrícola, a definição do QL é a seguinte?:

$$
Q L_{i j}=\left(S_{i j} / S_{i^{*}}\right) /\left(A_{* j} / A_{* *}\right)
$$

Em que:

$S_{i j}=$ área com soja na mesorregião $j$.

$S_{i}^{*}=$ área com soja em todas as mesorregiões.

$A_{* j}=$ área agrícola na mesorregião $j$.

$A_{* *}=$ área agrícola em todas as mesorregiões.

$\left(S_{i j} / S_{i^{*}}\right)=$ participação da área com soja na mesorregião $j$ na área com soja em todas as mesorregiões. Ou seja, a importância relativa da mesorregião $j$ na área com soja;

7. Aqui utilizou-se uma medida arbitrária, mas coerente, que foi a média da quantidade (arredondada para mais) de clusters indicada pela análise visual dos gráficos dos testes pseudo-T e pseudo-F. Assim, por exemplo, caso para 1994 o primeiro teste tenha indicado 4 e o segundo 1 , a quantidade escolhida seria 3.

8. Essa medida é consagrada nesta metodologia (MINGOTI, 2005; SAS, 2015a).

9. Baseado em Haddad (1989), que desenvolve uma discussão sobre o quociente locacional. 
Figura 1. Área de concentração originária do CGL

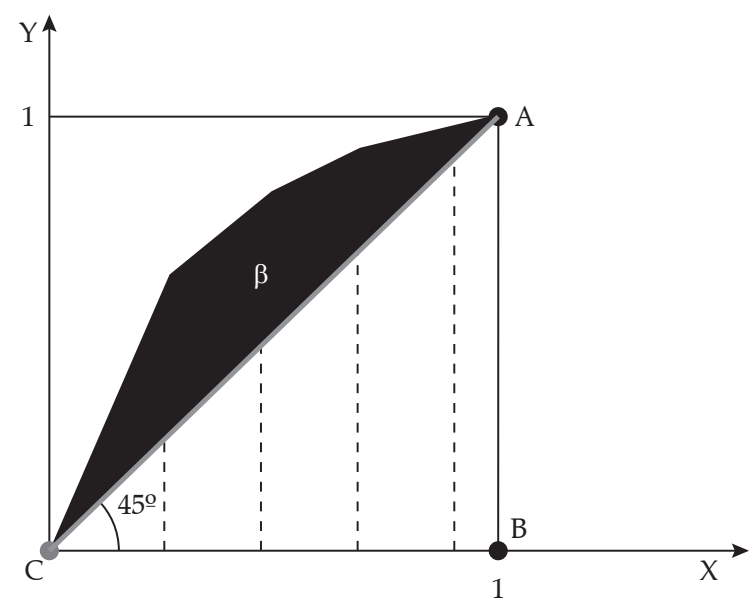

Fonte: Elaboração própria com base em Krugman (1991) e Suzigan et al. (2003).

$\left(A_{* j} / A_{* *}\right)=$ participação da área agrícola na mesorregião $j$ na área agrícola em todas as mesorregiões. $\mathrm{Ou}$, ainda, a importância relativa da mesorregião j na área agrícola em todas as mesorregióes.

O QL indicará se a importância relativa da mesorregião é maior para a soja do que para o conjunto das lavouras (permanentes e temporárias). Calculados os QL, pode-se calcular o CGL. O Coeficiente é útil para analisar a concentração espacial da leguminosa em uma área geográfica, ou seja, aferir se a soja está se especializando numa determinada base geográfica.

Ao trabalhar com grandes regiões, o primeiro passo é ordená-las por ordem decrescente do QL a partir de uma variável de escolha (área com soja, por exemplo). Então, se constrói uma curva de localização para a lavoura de interesse, definidos os pontos geradores da curva da seguinte forma:

- As coordenadas de y (Y) são dadas pelas porcentagens acumuladas da variável base em uma lavoura de interesse (soja), pelas mesorregiões;

- As coordenadas de x (X) são porcentagens acumuladas dessa mesma variável para todas as lavouras (temporária e permanente), pelas mesorregiões.

Em ambos os casos, a ordem de entrada dos dados é referida pelo ordenamento decrescente do QL. No caso hipotético da análise de cinco mesorregiões, a curva final contemplaria cinco pontos, como na Figura 1.

O CGL é a razão entre a área dada por $\beta$ (acima) e a área do triângulo $\mathrm{ABC}$, referido por uma reta de $45^{\circ}$ entre os eixos. Por essa construção e com base na Figura 1, observa-se que:

$$
C G L=(\beta / 0,5)=2 . \beta
$$

No limite, o $C G L=1$ porque o máximo valor de $\beta$ é dado por $0 \leq \beta \leq 0,5$.

Conforme Suzigan et al. (2003) quanto mais próximo de 1 (um), mais concentrada territorialmente a lavoura sob análise, e vice-versa. No caso de um país de dimensões continentais como o Brasil, o CGL tenderá a ser relativamente baixo por conta do vasto espaço territorial devido a cada uma de suas mesorregiões. ${ }^{10}$

Tal procedimento fora utilizado no estudo de Freitas, Mendonça e Lopes (2011) e investigou as áreas de fronteira agrícola. Também com esta temática, Carvalho, Laureto e Pena (2015) inves-

10. Duas observações de Krugman (1991) são oportunas. Primeiramente, os critérios de classificação dos órgãos de estatísticas são, em alguma medida, arbitrários e condicionam o resultado obtido. Estas classificações nem sempre acompanham o dinamismo típico de produções em expansão. Em segundo lugar, delimitações administrativas não necessariamente correspondem aos limites que captam a ocorrência de fenômenos econômicos. 
tigaram o desempenho de produtividade agrícola por microrregião brasileira, no conceito de produtividade total dos fatores. Em sua análise, os autores mapearam dois períodos distintos (1990-2000, 2001-2012) e concluíram que as culturas de soja, milho, café e algodão obtiveram melhores resultados entre 1990-2000 na comparação com o segundo subperíodo, enquanto cana-de-açúcar e mandioca apresentaram estagnação nos dois momentos.

O QL e o CGL são uma abordagem metodológica de localização devida inicialmente a Isard (1960). Posteriormente, Isserman (1977) apresentou fundamentação teórica para o uso de quocientes locacionais na estimativa regional de impactos econômicos. O autor sugeriu algumas modificações para melhorar a precisão de multiplicador econômico e concluiu que o QL pode ser uma ferramenta útil de planejamento, superando, assim, críticas de alguns autores quanto a uma suposta falta de acurácia do instrumento.

Desde então, tem sido tradicionalmente empregado em estudos de desenvolvimento regional. Krugman (1991) aplicara esta ferramenta para avaliar diferenças no perfil de concentração da indústria no caso dos Estados Unidos, detectando ritmos distintos de crescimento por perfil da indústria daquele país.

Já Audretsch e Feldman (1996) testaram a importância da proximidade geográfica para a ocorrência de efeitos de transbordamento (spillovers). A evidência empírica sugere que, até mesmo após controlar o grau de concentração da produção, a atividade inovativa tende a se aglomerar mais em firmas onde os spillovers perfazem um papel decisivo.

Na linha do estudo de Krugman (1991), outros trabalhos (BERTINELLI e DECROP, 2005; VAN DEN HEUVEL, DE LANGEN e FRANSOO, 2011) também empregaram o CGL para avaliações de localização e ressaltaram a relativamente simples implementação e demanda de dados do método.

Por outro lado, Freitas e Alves (2006) empregaram o CGL para avaliar possível concentração recente dos serviços prestados à agropecuária no Centro-Oeste brasileiro, hipótese empiricamente rejeitada a partir de dados da Pesquisa Anual de
Serviços (PAS) do Instituto Brasileiro de Geografia e Estatística (IBGE).

No caso de Dalmás, Staduto e Willers (2007), os autores identificaram uma concentração da atividade produtiva de abate de frangos no Oeste Paranaense, de modo a reunir elementos para definir esta mesorregião como um cluster em tal atividade.

Já Suzigan et al. (2003) haviam usado este procedimento para delimitar sistemas locais de produção, com aplicação ilustrativa à indústria de calçados do estado de São Paulo e destacando os subsistemas de produção de Franca, Birigui e Jaú.

Este instrumental também foi usado em outras investigações além da agricultura como, por exemplo, identificação de grupamentos industriais (REZENDE e DINIZ, 2013; BITENCOURT e GUIMARÃES, 2012), co-concentrações tecnológicas (ZITTA et al., 1999) e identificação de concentrações de setores de alta tecnologia (DEVEREUX, GRIFFITH e SIMPSON, 2004).

\section{Resultados}

Esta seção está dividida em duas partes. A primeira é dedicada a apresentar o fenômeno do crescimento de área de uso agrícola no Brasil entre 1994 e 2013. Já a segunda etapa da seção busca medir como a soja participou neste processo.

\subsection{Crescimento de área de uso agrícola no Brasil}

O crescimento médio anual de área destinada à colheita entre os anos de 1994 a 2013 foi da ordem de $1,76 \%$ a.a. Conquanto tenham sido observados anos de recuo, a tendência foi de crescimento definido para a área agrícola no Brasil. Este percentual de longo prazo (duas décadas) está ligeiramente abaixo do crescimento anual médio de curto prazo (2008-2013), que foi da ordem de $2,05 \%$ a.a., sinalizando possível fôlego recente do fenômeno.

Tendo em vista a sazonalidade natural de produção agrícola e, por conseguinte, as possíveis reduções de uso de fatores em anos especí- 
Tabela 1. Área destinada à colheita no Brasil e crescimento entre os anos 1994-2013

\begin{tabular}{lcc}
\hline Ano & Área destinada à colheita (Hectares) & Crescimento $t_{t-1}$ \\
\hline 1994 & 52.815 .030 & - \\
1995 & 51.853 .110 & $-1,82 \%$ \\
1996 & 46.821 .814 & $-9,70 \%$ \\
1997 & 48.302 .405 & $3,16 \%$ \\
1998 & 48.509 .074 & $0,43 \%$ \\
1999 & 50.700 .694 & $4,52 \%$ \\
2000 & 51.819 .125 & $2,21 \%$ \\
2001 & 51.637 .167 & $-0,35 \%$ \\
2002 & 54.511 .629 & $5,57 \%$ \\
2003 & 58.460 .983 & $7,24 \%$ \\
2004 & 63.036 .966 & $7,83 \%$ \\
2005 & 64.319 .313 & $2,03 \%$ \\
2006 & 62.563 .908 & $-2,73 \%$ \\
2007 & 62.338 .730 & $-0,36 \%$ \\
2008 & 65.527 .804 & $5,12 \%$ \\
2009 & 65.721 .594 & $0,30 \%$ \\
2010 & 65.374 .591 & $-0,53 \%$ \\
2011 & 68.158 .023 & $4,26 \%$ \\
2012 & 69.196 .172 & $1,52 \%$ \\
2013 & 72.434 .134 & $4,68 \%$ \\
\hline & Média de $1994-2008$ & $1,65 \%$ \\
& Média de $2008-2013$ & $2,05 \%$ \\
& $1994-2013$ & $1,76 \%$ \\
\hline
\end{tabular}

Fonte: Elaboração dos autores com base em dados da PAM do IBGE.

ficos, os dados da Tabela 1 ilustram um gradativo aumento de uso do fator terra no caso brasileiro entre 1994 e 2013.

Uma observação deve ser registrada neste ponto. Também em relação à taxa de crescimento optou-se por uma solução de parcimônia com o uso da média aritmética de crescimento entre os anos observados, opção que pode ser sofisticada. ${ }^{11}$

Para níveis mais agregados, a ocorrência do registro de valores nulos para as variáveis de área agrícola é raro. Em níveis mais desagregados, como microrregiões por cultura específica (em especial para as culturas de mercado interno, como feijão e borracha, por exemplo), reconhece-se que o uso da taxa geométrica de crescimento pode ser uma opção superior ao uso da média

11. A título de comparação, a taxa geométrica de crescimento da área destinada à colheita no Brasil foi da ordem de 1,55\% a.a. entre 1994 e 2008; 2,02\% a.a. entre 2008 e 2013; e 1,68\% a.a. entre 1994 e 2013. Em regra, representam uma suavização do crescimento dos dados e seu uso pode ser substancialmente válido em desagregações para culturas de mercado doméstico, item para agenda de investigação futura. aritmética de crescimento entre os anos, em especial na comparação entre um grande número de culturas de consumo prioritariamente doméstico.

$\mathrm{O}$ uso da mesorregião num primeiro instante também se ampara em Briant, Combes e Lafourcade (2010), segundo os quais níveis mais desagregados de informação tendem a resultar em maior número de áreas sem registro de informação. Devereux, Griffith e Simpson (2004) apresentam estratégias quando da presença de áreas sem registro de informação em investigação com níveis regionais mais desagregados. Segundo estes autores, pode-se calcular o CGL apenas com as regiões nas quais há registro de informação ou empregar o valor zero para as áreas onde a informação não tem registro. ${ }^{12}$

12. Embora não se aplique imediatamente ao presente estudo devido à grande abrangência geográfica da soja pelas mesorregiões brasileiras, é intenção dos autores aplicar este procedimento quando da extensão deste trabalho de modo a incluir safras típicas de mercado interno e outras variáveis (receita, emprego e quantidade produzida) para cada cultura. 
Tabela 2. Número de grupamentos de mesorregiões agrícolas no Brasil, 1994-2013

\begin{tabular}{|c|c|c|c|c|c|c|c|c|c|}
\hline \multirow{2}{*}{ Período } & \multicolumn{3}{|c|}{ Variáveis em nível (N) } & \multicolumn{3}{|c|}{ Variáveis em taxa de crescimento $(\mathrm{T})$} & \multicolumn{3}{|c|}{ Variáveis normalizadas (NO) } \\
\hline & Pseudo-F & Pseudo-T & Média & Pseudo-F & Pseudo-T & Média & Pseudo-F & Pseudo-T & Média \\
\hline 1994 & 3 & 2 & 2,5 & - & - & - & 3 & 2 & 2,5 \\
\hline 1995 & 3 & 2 & 2,5 & 5 & 3 & 4,0 & 5 & 4 & 4,5 \\
\hline 1996 & 4 & 3 & 3,5 & 6 & 4 & 5,0 & 4 & 3 & 3,5 \\
\hline 1997 & 4 & 3 & 3,5 & 5 & 5 & 5,0 & 4 & 3 & 3,5 \\
\hline 1998 & 3 & 2 & 2,5 & 3 & 2 & 2,5 & 5 & 3 & 4,0 \\
\hline 1999 & 3 & 2 & 2,5 & 5 & 5 & 5,0 & 5 & 4 & 4,5 \\
\hline 2000 & 4 & 5 & 4,5 & 5 & 4 & 4,5 & 3 & 2 & 2,5 \\
\hline 2001 & 4 & 6 & 5,0 & 4 & 3 & 3,5 & 4 & 3 & 3,5 \\
\hline 2002 & 4 & 5 & 4,5 & 4 & 3 & 3,5 & 5 & 4 & 4,5 \\
\hline 2003 & 6 & 4 & 5,0 & 3 & 5 & 4,0 & 3 & 2 & 2,5 \\
\hline 2004 & 6 & 4 & 5,0 & 3 & 2 & 2,5 & 3 & 5 & 4,0 \\
\hline 2005 & 4 & 5 & 4,5 & 5 & 4 & 4,5 & 5 & 3 & 4,0 \\
\hline 2006 & 3 & 2 & 2,5 & 5 & 3 & 4,0 & 3 & 2 & 2,5 \\
\hline 2007 & 3 & 2 & 2,5 & 3 & 2 & 2,5 & 4 & 3 & 3,5 \\
\hline 2008 & 4 & 3 & 3,5 & 4 & 2 & 3,0 & 3 & 2 & 2,5 \\
\hline 2009 & 4 & 5 & 4,5 & 3 & 2 & 2,5 & 4 & 2 & 3,0 \\
\hline 2010 & 4 & 5 & 4,5 & 4 & 3 & 3,5 & 5 & 2 & 3,5 \\
\hline 2011 & 4 & 5 & 4,5 & 3 & 2 & 2,5 & 3 & 2 & 2,5 \\
\hline 2012 & 4 & 3 & 3,5 & 3 & 2 & 2,5 & 3 & 2 & 2,5 \\
\hline 2013 & 4 & 3 & 3,5 & 3 & 2 & 2,5 & 6 & 5 & 5,5 \\
\hline
\end{tabular}

Fonte: Elaboração dos autores com base em dados da PAM do IBGE.

Neste diapasão, conforme Reveiu e Dardala (2011), a seleção de um tipo específico de método depende do tipo de relação que se pretende identificar entre os indivíduos de um conjunto de dados. Para estes mesmos autores, o CGL é uma das opções recomendadas para determinar se um setor ou atividade está concentrado geograficamente em escala nacional.

Dado o objetivo inicial aqui delimitado, o CGL e o QL se enquadram como candidatos iniciais naturais justamente por conta da natureza acessível dos dados em regra demandados, do caráter direto de seus cálculos e da interpretação prática de seus resultados. Ademais, o uso da mesorregião como base territorial de análise não impede que análises posteriores investiguem níveis mais desagregados territorialmente.

Isto posto, foram filtradas para análise apenas as mesorregiões que apresentaram indicadores (1) e (2) da metodologia acima da respectiva média nacional, vale dizer, $I_{1}$ maior que $11,74 \%$ e $I_{2}$ maior que $29,09 \%$. Destarte, dentre as 137 mesorregiões brasileiras, 42 atenderam aos dois critérios.
Já nos procedimentos de análise de grupamentos obteve-se um máximo de seis grupamentos consoante os testes Pseudo T e Pseudo F efetuados. Os resultados estão ilustrados na Tabela 2, dados gerados com base em SAS (2015b, 2015c).

Selecionadas as 42 mesorregiões, à medida que os valores sugeridos pelos testes limitaram em até seis grupamentos homogêneos entre si, os mesmos foram categorizados de acordo com o crescimento participativo de cada mesorregião entre os anos extremos da série (1994 e 2013) disponível, de modo a que as mesorregiões fossem agrupadas com base no ganho de participação dentro de intervalo de tempo disponível para avaliação.

Elas foram subdivididas em: i) aquelas que mais do que dobraram a participação na área agrícola brasileira (Área 1); ii) as que aumentaram entre 1 e 2 vezes (Área 2); iii) as que aumentaram entre 0,5 e 1 vez (Área 3); iv) as que aumentaram até 0,5 vez (Área 4); e v) aquelas que experimentaram pequeno recuo participativo no cotejo entre os anos-limite da série (Área 5). A Área 6 seria composta pelas mesorregiões não selecionadas. 
Tabela 3. Participação das mesorregiões selecionadas na área agrícola em 1994 e 2013

\begin{tabular}{|c|c|c|c|c|}
\hline & Part.\% 1994 (A) & Part.\% 2013 (B) & $C=(B / A)-1$ & \\
\hline Norte do Amapá - AP & $0,001 \%$ & $0,011 \%$ & 6,60 & \multirow{7}{*}{ Área 1} \\
\hline Oriental do Tocantins - TO & $0,126 \%$ & $0,630 \%$ & 4,00 & \\
\hline Sul do Amapá - AP & $0,006 \%$ & $0,027 \%$ & 3,32 & \\
\hline Norte Mato-grossense - MT & $3,092 \%$ & $11,573 \%$ & 2,74 & \\
\hline Sul Maranhense - MA & $0,292 \%$ & $1,033 \%$ & 2,54 & \\
\hline Nordeste Mato-grossense - MT & $0,689 \%$ & $2,305 \%$ & 2,35 & \\
\hline Sul Amazonense - AM & $0,019 \%$ & $0,057 \%$ & 2,04 & \\
\hline Extremo Oeste Baiano - BA & $1,211 \%$ & $2,537 \%$ & 1,10 & \multirow{3}{*}{ Área 2} \\
\hline Vale do Juruá - AC & $0,033 \%$ & $0,067 \%$ & 1,06 & \\
\hline Leste Goiano - GO & $0,571 \%$ & $1,152 \%$ & 1,02 & \\
\hline Sudoeste de Mato Grosso do Sul - MS & $2,146 \%$ & $4,134 \%$ & 0,93 & \multirow{9}{*}{ Área 3} \\
\hline Sudoeste Piauiense - PI & $0,655 \%$ & $1,235 \%$ & 0,89 & \\
\hline Presidente Prudente - SP & $0,503 \%$ & $0,898 \%$ & 0,78 & \\
\hline Sudeste Mato-grossense - MT & $1,834 \%$ & $3,038 \%$ & 0,66 & \\
\hline Noroeste Paranaense - PR & $0,676 \%$ & $1,113 \%$ & 0,65 & \\
\hline Sul Goiano - GO & $3,585 \%$ & $5,766 \%$ & 0,61 & \\
\hline Centro-Sul Mato-grossense - MT & $0,167 \%$ & $0,267 \%$ & 0,60 & \\
\hline Araçatuba - SP & $0,543 \%$ & $0,846 \%$ & 0,56 & \\
\hline Norte de Roraima - RR & $0,037 \%$ & $0,057 \%$ & 0,53 & \\
\hline Centro Amazonense - AM & $0,106 \%$ & $0,155 \%$ & 0,46 & \multirow{21}{*}{ Área 4} \\
\hline Noroeste de Minas - MG & $0,821 \%$ & $1,192 \%$ & 0,45 & \\
\hline Centro Ocidental Rio-grandense - RS & $0,904 \%$ & $1,264 \%$ & 0,40 & \\
\hline Centro Norte de Mato Grosso do Sul - MS & $0,782 \%$ & $1,081 \%$ & 0,38 & \\
\hline Sudoeste Mato-grossense - MT & $0,340 \%$ & $0,459 \%$ & 0,35 & \\
\hline Nordeste Rio-grandense - RS & $0,612 \%$ & $0,791 \%$ & 0,29 & \\
\hline Triângulo Mineiro/Alto Paranaíba - MG & $2,189 \%$ & $2,828 \%$ & 0,29 & \\
\hline Centro Oriental Paranaense - PR & $0,998 \%$ & $1,279 \%$ & 0,28 & \\
\hline Bauru - SP & $0,953 \%$ & $1,213 \%$ & 0,27 & \\
\hline Sudoeste Amazonense - AM & $0,021 \%$ & $0,027 \%$ & 0,27 & \\
\hline Marília - SP & $0,163 \%$ & $0,205 \%$ & 0,26 & \\
\hline Sul de Roraima - RR & $0,024 \%$ & $0,029 \%$ & 0,23 & \\
\hline Baixo Amazonas - PA & $0,241 \%$ & $0,294 \%$ & 0,22 & \\
\hline Sudoeste Rio-grandense - RS & $1,179 \%$ & $1,427 \%$ & 0,21 & \\
\hline São José do Rio Preto - SP & $1,388 \%$ & $1,669 \%$ & 0,20 & \\
\hline Distrito Federal - DF & $0,159 \%$ & $0,189 \%$ & 0,19 & \\
\hline Norte Pioneiro Paranaense - PR & $1,308 \%$ & $1,478 \%$ & 0,13 & \\
\hline Itapetininga - SP & $0,674 \%$ & $0,720 \%$ & 0,07 & \\
\hline Sudeste Paranaense - PR & $0,833 \%$ & $0,885 \%$ & 0,06 & \\
\hline Madeira-Guaporé - RO & $0,072 \%$ & $0,075 \%$ & 0,04 & \\
\hline Norte Central Paranaense - PR & $2,446 \%$ & $2,518 \%$ & 0,03 & \\
\hline Centro Ocidental Paranaense - PR & $1,607 \%$ & $1,599 \%$ & $-0,01$ & \multirow{2}{*}{ Área 5} \\
\hline Nordeste Baiano - BA & $1,027 \%$ & $0,874 \%$ & $-0,15$ & \\
\hline Subgrupo I1 e I2 & $35,032 \%$ & $58,998 \%$ & 0,68 & \\
\hline Total Brasil & $100 \%$ & $100 \%$ & & \\
\hline
\end{tabular}

Fonte: Elaboração dos autores com base em dados da PAM do IBGE. 
Em linha com tal procedimento ${ }^{13}$, os dados da Tabela 3 informam uma hierarquia de expansão da área agrícola entre as mesorregiões selecionadas, conforme os critérios acima delineados e referidos na metodologia.

$\mathrm{Na}$ Tabela 3, o valor 4,0 verificado para a mesorregião oriental de Tocantins denota que sua participação na área agrícola em 2013 era 5,0 vezes a sua participação no ano-base de análise, 1994. Raciocínio análogo aplica-se a todos os valores registrados na coluna $\mathrm{C}$.

Observa-se que predomina uma dinâmica de expansão de área agrícola pela rota Centro Noroeste do País com projeções relativamente bem definidas na direção dos trechos ocidentais e meridionais da região Norte. Além disso, existe um subeixo definido de incrementos de áreas, com base nas mesorregiões do nordeste mato-grossense, norte mato-grossense, sul amazonense, e Vale do Juruá, de modo a atingir novamente um dinamismo expressivo no estado do Amapá que se configura como fronteira em expansão.

Outra observação refere-se a ganhos de área entre as regiões Nordeste e Norte, com núcleo nas mesorregiões de oriental de Tocantins, sul maranhense, sudoeste piauiense e extremo oeste baiano; e também trechos com ritmo intermediário de expansão de área no norte do PR, oeste paulista, cercanias do DF (GO), e centro sul de MS.

Estes comentários estão ilustrados na Figura 2.

Uma limitação do estudo que deve ficar anotada é que em mesorregiões de menor área total e com pequena área agrícola em 1994, como no caso do Amapá, partiu-se de uma base de comparação relativamente menor do que no caso de mesorregiões maiores, a exemplo daquelas do Centro-Oeste e dos estados de MA, TO, PI e BA.

Outra ressalva necessária liga-se ao fato de que a não inclusão de variáveis de preço da terra e de produto ${ }^{14}$ - não disponíveis para cada

13. Tal medida pode ser refinada futuramente por meio da ponderação (inversa) do valor obtido, conforme a base de comparação seja maior ou menor para cada área, o que pode ser útil para níveis mais desagregados geograficamente, como microrregião ou município.

14. Nesta tônica, de acordo com Leite e Wesz (2010), houve variações no preço de compra e venda das áreas com mesorregião - pode subestimar a diferença entre o ritmo de expansão das novas áreas do Centro-Oeste e as do Norte em comparação com as áreas tradicionais e consolidadas do Sul e de São Paulo e Minas Gerais.

\subsection{Cultura da soja na expansão de área agrícola brasileira}

Enquanto o crescimento médio anual de área agrícola no Brasil (todas as culturas agrícolas) foi da ordem de $1,76 \%$ a.a., no caso da soja este valor foi de $5,06 \%$ a.a. Ao mesmo tempo, o crescimento médio anual de área agrícola entre 2008 e 2013 foi ainda mais expressivo, de 5,68\% a.a, contra 2,05\% para o caso geral. Os dados da Tabela 4 sintetizam o crescimento de área agrícola de soja no Brasil entre os anos de 1994 a $2013^{15}$.

Tomando-se as 42 mesorregiões identificadas no subitem precedente, calculou-se a participação das mesmas na área de soja e na área para o total das lavouras. Os resultados, de acordo com os dados da Figura 3, mostram que as mesorregiões identificadas foram concentradoras do total de solo para uso agrícola no caso geral da lavoura, saindo de 35\% em 1994 para 59\% em 2013. Ao mesmo tempo, esta concentração foi também marcante no caso da leguminosa, dado que as mesorregiões mapeadas passaram a responder por $73 \%$ da área de soja no País em 2013, contra 58\% em 1994.

Embora esteja ocorrendo uma expansão da área empregada com a cultura da soja, Bruce e Carriquiry (2010), em análise que dividira o Brasil em seis áreas de produção agrícola, já haviam detectado que variações na área cultivada não produzem queda na produtividade da leguminosa. Este processo possivelmente associa-se ao grau de tecnificação e padronização para o cultivo da soja. Sob este aspecto, desde os anos da

lavouras e um acréscimo nos preços de áreas com pastagens, que são em seguida convertidas em novas áreas abertas para o cultivo da soja, além do algodão.

15. Em termos da taxa geométrica de crescimento de área para soja obtiveram-se os valores de $4,46 \%$ a.a. entre 1994 e 2008; 5,63\% a.a. entre 2008 e 2013 e 4,76\% a.a. entre 1994 e 2013. 


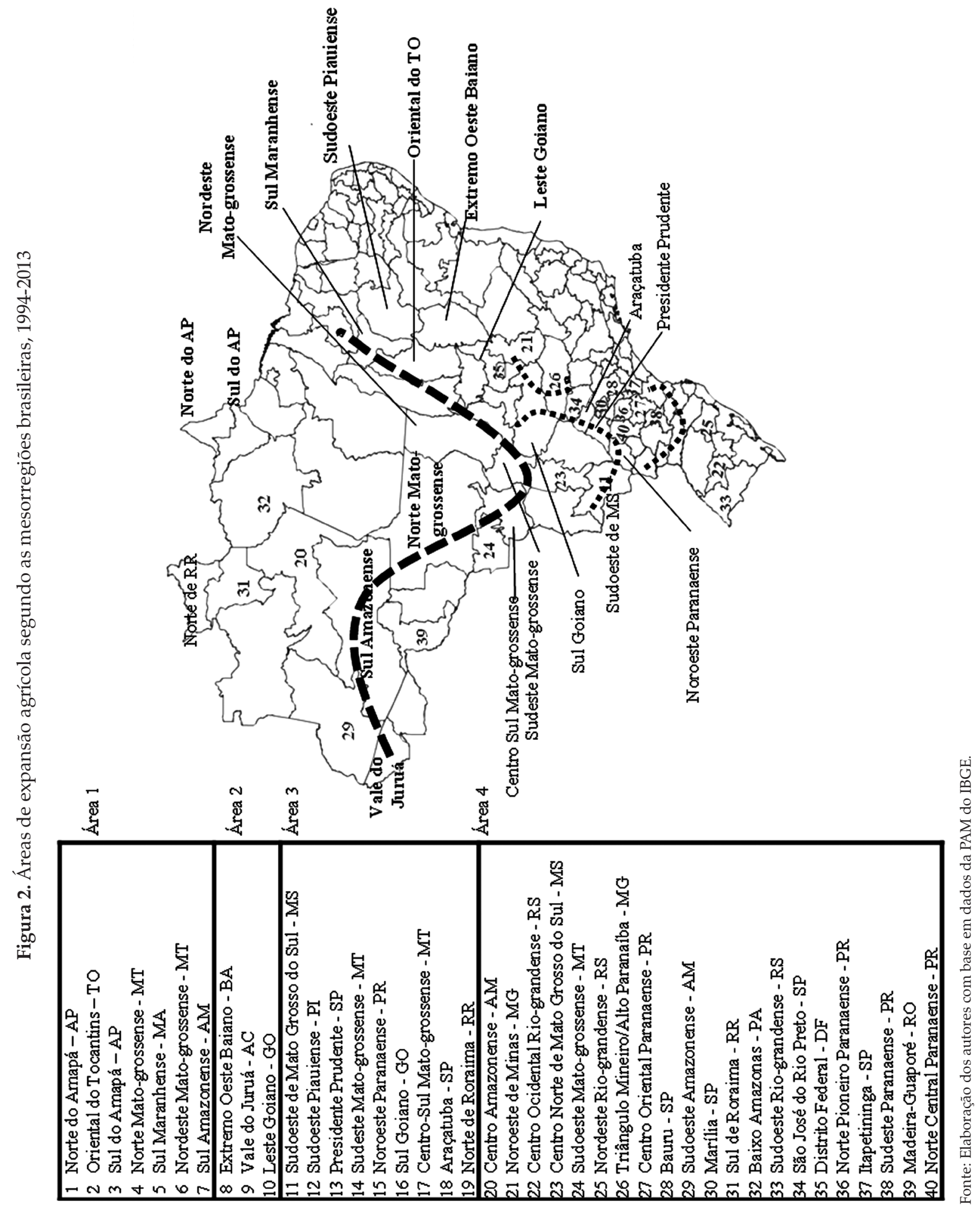


Tabela 4. Área destinada à colheita de soja e crescimento entre os anos, 1994-2013

\begin{tabular}{lrc}
\hline Ano & Área destinada à colheita (Hectares de soja) & Crescimento $_{t^{t}-1}$ \\
\hline 1994 & 11.544 .577 & - \\
1995 & 11.702 .919 & $1,37 \%$ \\
1996 & 10.356 .156 & $-11,51 \%$ \\
1997 & 11.508 .120 & $11,12 \%$ \\
1998 & 13.319 .749 & $15,74 \%$ \\
1999 & 13.069 .793 & $-1,88 \%$ \\
2000 & 13.693 .677 & $4,77 \%$ \\
2001 & 13.988 .351 & $2,15 \%$ \\
2002 & 16.376 .035 & $17,07 \%$ \\
2003 & 18.527 .544 & $13,14 \%$ \\
2004 & 21.601 .340 & $16,59 \%$ \\
2005 & 23.426 .756 & $8,45 \%$ \\
2006 & 22.082 .666 & $-5,74 \%$ \\
2007 & 20.571 .393 & $-6,84 \%$ \\
2008 & 21.252 .721 & $3,31 \%$ \\
2009 & 21.761 .782 & $2,40 \%$ \\
2010 & 23.339 .094 & $7,25 \%$ \\
2011 & 24.032 .410 & $2,97 \%$ \\
2012 & 25.090 .559 & $4,40 \%$ \\
2013 & 27.948 .605 & $11,39 \%$ \\
\hline & Média de $2008-2013$ & $4,84 \%$ \\
& $1994-2013$ & $5,68 \%$ \\
& & $5,06 \%$ \\
\hline
\end{tabular}

Fonte: Elaboração dos autores com base em dados da PAM do IBGE.

Figura 3. Participação das mesorregiões identificadas na área de soja e na área total das lavouras

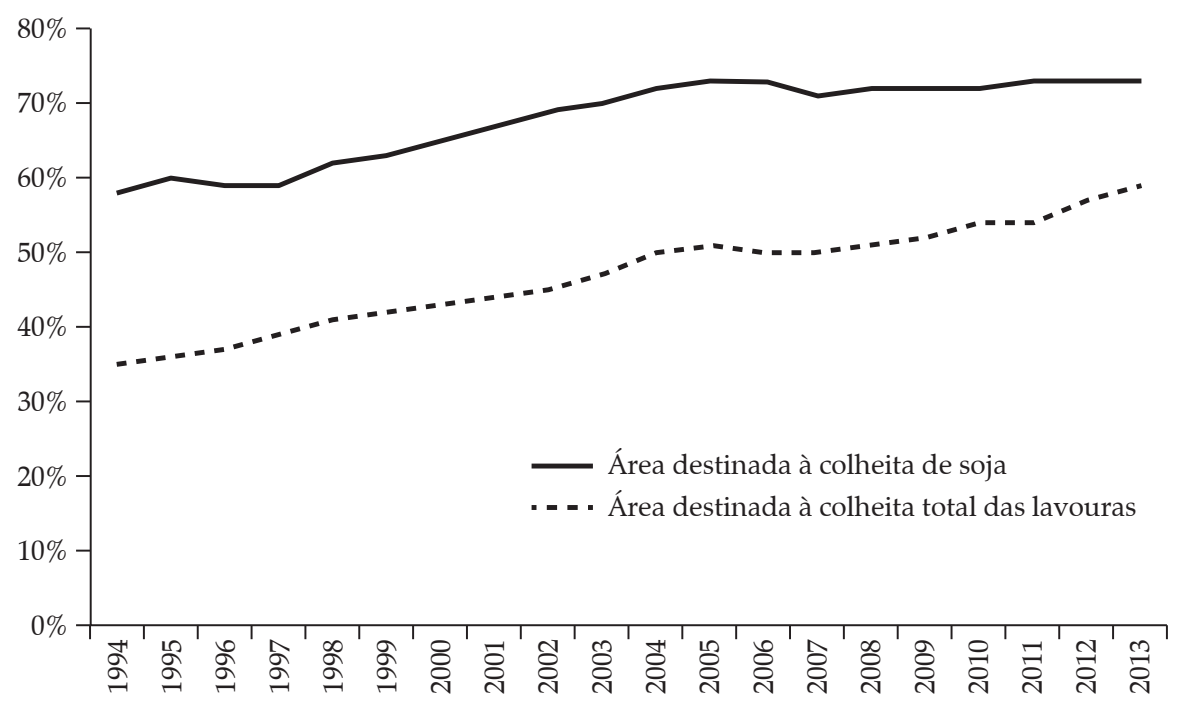

Fonte: Elaboração dos autores com base em dados da PAM do IBGE. 
década de 1970 o Centro-Oeste já era a região do País em que a produtividade total dos fatores crescia mais rapidamente (HELFAND e LEVINE, 2004).

No que pertine ao CGL, os dados mostram que a expansão de área agrícola com o perfil das 42 mesorregiões identificadas foi mais concentrada no sentido da soja do que no sentido do conjunto das lavouras temporárias ${ }^{16}$. Isto é, este perfil de expansão de área agrícola tem sido soja concentrado particularmente quando se avalia o CGL médio para a lavoura temporária $(0,043)$ contra o CGL médio para a soja $(0,295)$.

Sobre o parágrafo anterior, há que se observar os dados da Tabela 5, a seguir.

Em particular acerca do papel declinante ou estabilizado da soja nas áreas selecionadas pós 2009, outro lado do fenômeno é dado pela observação da participação da soja na área total de lavouras temporárias nas mesorregiões não selecionadas. Esta informação está representada na Figura 4, a seguir.

Nota-se que nas mesorregiões não selecionadas a soja expandiu-se no total de áreas ocupadas pelas lavouras temporárias. Este dado, aliado às informações da Tabela 5 , sugere que um desdobramento necessário deste estudo seria compreender melhor o papel das lavouras permanentes nas mesorregiões de área agrícola estabilizada.

Outro dado que caracteriza o papel da soja na dinâmica de expansão das mesorregiões selecionadas é o fato de haver um Quociente Locacional (QL) de tendência declinante para as demais mesorregiões (não selecionadas), conforme a Figura 5, a seguir. Ou seja, considerando-se o peso das mesorregiões não selecionadas na expansão de área agrícola da soja.

Também há um arrefecimento do fenômeno a partir de 2009, somado à baixa variabilidade do

16. Grupo de lavouras que inclui a soja, além de abacaxi, algodão herbáceo, alho, amendoim, arroz, aveia, batata-doce, batata-inglesa, cana-de-açúcar, cebola, centeio, cevada, ervilha, fava, feijão, fumo, juta, linho, malva, mamona, mandioca, melancia, melão, milho, rami, sorgo granífero, tomate e trigo. Portanto, não contabiliza as lavouras permanentes. indicador quando comparado à média da série $(0,601)$, o que pode significar que a expansão de área nas mesorregiões selecionadas esteja sendo menos concentrado na leguminosa especificamente após 2009, hipótese que somente novos dados permitirão avaliar melhor.

No que tange à soja, segundo Sauer e Leite (2012), a área ocupada pela expansão da leguminosa em direção aos Cerrados e à Amazônia tem sido obtida às custas do desmatamento. Este raciocínio é esposado por Ferreira e Coelho (2015), especificamente no que se refere aos estados da Amazônia Legal.

Ao mesmo tempo, cumpre lembrar que $67 \%$ da soja nacional é escoada por rodovias (ALMEIDA, SELEME e NETO, 2013), e como há indicadores de que este quadro é parte de uma perda de 13\% de cada safra de soja (NAVES, 2009 apud ALMEIDA, SELEME e NETO, 2013), a continuidade de expansão da fronteira agrícola com ênfase na leguminosa deve ser repensada não só em termos do desmatamento eventualmente associado, mas também quanto à operacionalização de estratégias alternativas de transporte interno do grão.

Igualmente, é preciso registrar que parte da soja produzida no País é usada no arraçoamento de animais e convertida em carnes e lácteos para os mercados domésticos inclusive. ${ }^{17}$ Consoante Fernandes et al. (2012), que estudaram o estado de GO, a parte da soja que se destina à produção do biodiesel representa apenas $20 \%$ do grão.

Embora estudos como Câmara et al. (2015) avaliem que o Brasil tem condições de conciliar a preservação ambiental e redução de emissões de gases de efeito estufa com seu papel de grande produtor de alimentos, em certa medida este ainda é um debate em aberto.

17. Uma sinalização importante está em Pinto e Sparovek (2015), em que os autores projetam para o período 2014 a 2020 a produção de proteína e energia devidas à agricultura e à pecuária, concluindo que o valor de produção da agricultura é relativamente pequeno face a sua produção de proteína e de energia, donde o mercado não refletiria adequadamente a funcionalidade, eficiência e impacto diferenciados entre pecuária e agricultura. 
Tabela 5. CGL para a soja e CGL para a lavoura temporária

\begin{tabular}{ccc}
\hline Ano & CGL soja & CGL lavoura temporária \\
\hline 1994 & 0,301 & 0,026 \\
1995 & 0,321 & 0,028 \\
1996 & 0,292 & 0,030 \\
1997 & 0,283 & 0,033 \\
1998 & 0,296 & 0,038 \\
1999 & 0,293 & 0,038 \\
2000 & 0,306 & 0,039 \\
2001 & 0,318 & 0,041 \\
2002 & 0,320 & 0,042 \\
2003 & 0,317 & 0,041 \\
2004 & 0,300 & 0,041 \\
2005 & 0,296 & 0,117 \\
2006 & 0,317 & 0,044 \\
2007 & 0,293 & 0,043 \\
2008 & 0,298 & 0,043 \\
2009 & 0,299 & 0,048 \\
2010 & 0,279 & 0,045 \\
2011 & 0,277 & 0,043 \\
2012 & 0,253 & 0,044 \\
2013 & 0,234 & 0,043 \\
Média & 0,295 & 0,043 \\
\hline
\end{tabular}

Fonte: Elaboração dos autores com base em dados da PAM do IBGE.

Figura 4. Participação da área de soja na área total de lavouras temporárias nas mesorregiões não selecionadas

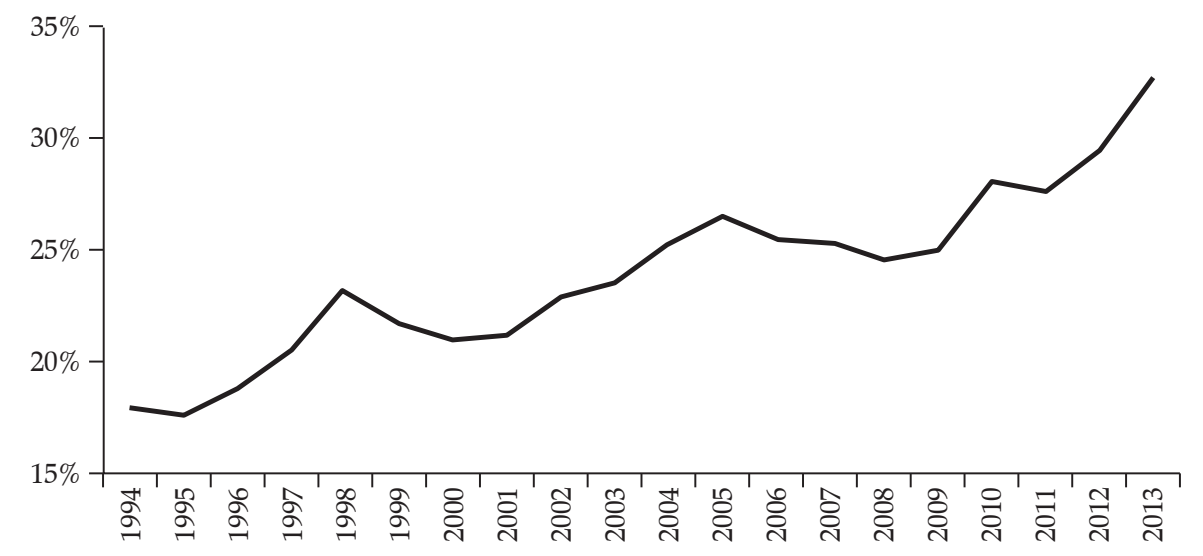

Fonte: Elaboração dos autores com base em dados da PAM do IBGE. 
Figura 5. Quociente Locacional das mesorregiões não selecionadas para a soja

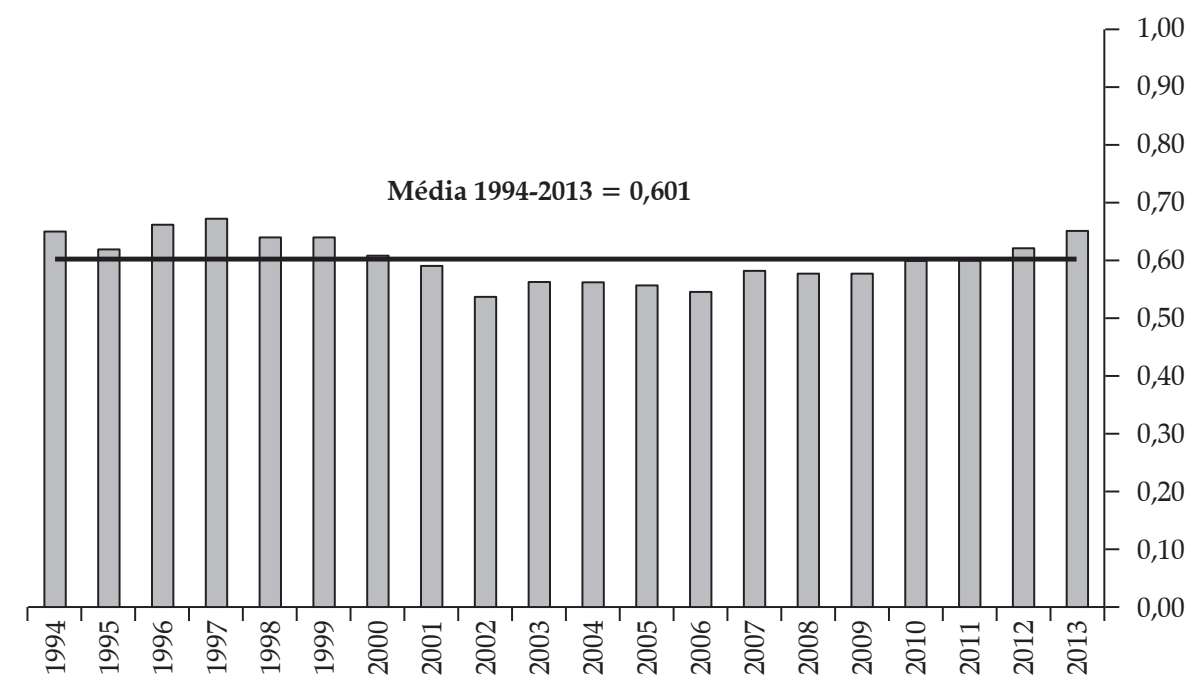

Fonte: Elaboração dos autores com base em dados da PAM do IBGE.

O que se deve reter é que a expansão da produção de grãos guarda possível impacto indireto no espaço disponível à produção de itens alimentares domésticos componentes da cesta de consumo alimentar local.

Neste quesito, trabalho recente (SPAROVEK et al., 2016) mostra que ganhos de eficiência são uma questão importante para os produtores de menor porte e nível de renda. Assim, investigações adicionais ainda são necessárias, sobretudo em maiores desagregações territoriais (município, por exemplo), que é justamente uma limitação do presente trabalho.

Evidente que tais impactos no caso da expansão da soja não se restringem à competição por fatores agrícolas. Um caso clássico é o do município de Sorriso (MT) (BRUM, DALFOVO e AZUAGA, 2009), onde fica claro que a comunidade local, por um lado, tem se beneficiado do crescimento econômico acelerado oriundo da expansão da fronteira agrícola, mas, por outro lado, se depara também com um nível maior de degradação ambiental, em detrimento das gerações futuras.

Isto posto, algumas ponderações acerca dos instrumentos aqui usados devem ser colocadas. Na linha do trabalho de Crocco et al. (2006), o QL deve ser tomado com cautela, visto que a interpretação de seu resultado deve levar em conta as características da economia em tela. Os autores, com razão, pontuam que o indicador apresenta resultados mais adequados em áreas com estrutura produtiva mais diversificada. Por outro lado, a própria simplicidade na operacionalização do QL e do CGL devem ser entendidas como uma limitação. Ferramentas complementares elaboradas para níveis mais desagregados de informação (municípios ou microrregiões, por exemplo) devem ser implementadas em versões posteriores desta análise.

Um prolongamento deste estudo seria avaliar o indicador da soja comparativamente ao indicador para outras culturas temporárias. Mutatis mutandis, o milho seria um candidato imediato dada a reconhecida rotação de culturas no caso da sojicultora, além da vinculação milho-soja para o arraçoamento de aves e suínos seja para fins de exportação ou de suprimento interno.

Outra extensão necessária é aquela sugerida em Ruan e Zhang (2014), em que os autores calcularam o CGL baseado em três variáveis (receita, emprego e produção total) no contexto da mudança de localização geográfica dos setores industriais na China. Aqui, Lu, Flegg e Deng 
(2011) também alertam para a limitação do CGL em captar a concentração de atividade em indústrias em que a localização da sede industrial tem impacto na alocação de receitas e despesas das filiais, mesmo que situadas em outra base geográfica. ${ }^{18}$

Nesta linha, Helfand, Moreira e Figueiredo (2011) utilizaram índices para denotar a qualidade do solo em características tidas como relevantes e contemplaram variáveis de temperatura e precipitação, fertilidade do solo, drenagem, resistência à erosão, potencial para mecanização e capacidade de enraizamento, a partir dos trabalhos do Prof. Gerd Sparovek (Esalq/USP).

Fica proposta uma extensão futura do caso da soja de modo a contemplar estas variáveis adicionais. Esta inclusão de novas variáveis de análise da leguminosa pode se beneficiar igualmente de indicadores de concentração, conforme a proposição de Crocco et al. (2006) ou de Van Den Heuvel et al. (2014).

Os exercícios sugeridos ampliariam a visão acerca de como tem se realizado a expansão da fronteira agrícola brasileira e da distribuição de área, produção, emprego e receita entre as principais culturas temporárias, podendo-se ampliar tais simulações ao caso das culturas permanentes.

\section{Considerações finais}

São grandes os desafios do século XXI no que tange à produção de alimentos. Nesta temática, $\mathrm{o}$ Brasil é um dos poucos países ainda capazes de expandir sua área de agricultura, mesmo considerando-se os inescapáveis requisitos de manejo ambiental.

Os resultados deste estudo mostram que, na expansão agrícola brasileira, está bem definida uma rota Centro Noroeste de ocupação de novos espaços. Neste movimento ressaltam-se trechos

18. Este é um detalhe significativo caso se deseje aprofundar a análise para o efeito da expansão da fronteira agrícola sobre a localização dos provedores de insumos e dos modais logísticos de escoamento da safra e/ou de seus processados. ocidentais da região Norte em associação com mesorregiões de oriental do Tocantins, sul maranhense e extremo oeste baiano e a ocupação de novas áreas no segmento sul da região Norte, em zonas de transição que estão centradas nas mesorregiões do norte e nordeste mato-grossenses.

Igualmente destacável é a intensificação de uso agrícola no norte do PR, oeste paulista, arredores do DF e centro-sul de MS. É possível que muitas áreas estejam sendo ocupadas mais intensamente por conta de incentivos econômicos e/ou de rearranjos produtivos locais que escapam ao fôlego do presente texto, o que pode representar futura agenda de investigações.

Identificada tal base de expansão de uso de área agrícola, procurou-se medir a participação da soja neste processo. Neste aspecto, os resultados do trabalho sinalizam para um perfil de expansão de área agrícola concentrado pela leguminosa, ainda que com menor intensidade a partir de 2009. Somente uma série mais extensa de dados poderá responder se o fenômeno se intensifica ou tende ao enfraquecimento.

Dada a rota de expansão de área agrícola no Brasil e a participação da soja neste fenômeno, os investimentos em transporte intermodal (rodovia/ ferrovia/hidrovia) tornam-se necessários para mitigar os elevados custos logísticos internos de transporte e também de chegada aos portos brasileiros.

Extensões posteriores deste estudo podem beneficiar-se do uso da taxa geométrica de crescimento anual combinada com análises em níveis territoriais mais desagregados. Ademais, as áreas de maior crescimento verificado podem também vir a ser ponderadas inversamente pela sua base de comparação, no intuito de suavizar o crescimento de regiões com área agrícola muito pequena no período base.

Análises futuras deverão incluir variáveis de explicação, como dados de deficiência hídrica, proporção de áreas irrigadas, qualidade das terras, características de infraestrutura e variáveis de políticas de crédito. Na mesma direção, também é válido analisar as condições de clima e solo, por meio de proxies representativas de aptidão agrícola das terras, por exemplo. 
É intenção dos autores que os resultados aqui obtidos sejam base atualizável para estudos posteriores com o friso de mapear as outras culturas agrícolas representativas nas mesorregiões aqui selecionadas. Estudos adicionais teriam no milho e no algodão candidatos naturais, além da comparação entre os grupos de lavouras permanente e temporária e do uso de indicadores de concentração mais sofisticados, consoante descrito no estudo.

Por fim, uma outra frente seria a análise dos padrões de produtividade das diversas culturas nas áreas de fronteira e nas áreas já estabilizadas, vez que há indícios de que as ondas de avanço no uso do solo não são homogêneas em produtividade se comparadas às regiões com ciclos já estabelecidos nas respectivas culturas agrícolas.

\section{Referências}

ALMEIDA, C. A., SELEME, R. e NETO, J. C. Rodovia Transoceânica: uma alternativa logística para o escoamento das exportações da soja brasileira com destino à China. Revista de Economia e Sociologia Rural, v. 51, n. 2, p.351-368, abr.jun. 2013. Disponível em: $<$ http://www.scielo.br/scielo.php?script=sci_arttext\& pid=S0103-20032013000200008>.

AUDRETSCH, D. e FELDMAN, M. R\&D Spillovers and the Geography of Innovation and Production. The American Economic Review, v. 86, n. 3, p. 630-640, jun. 1996.

BERTINELLI, L. e DECROP, J. Geographical agglomeration: Ellison and Glaser's index applied to the case of Belgian manufacturing industry. Regional Studies, v. 39, i. 5, p. 567-583, 2005.

BITENCOURT, R. S. e GUIMARAES, L. B. M. Aplicação do Coeficiente de Gini Locacional e do Quociente Locacional como apoio à delimitação geográfica de sistemas locais de produção: o setor coureiro calçadista do RS. Bento Gonçalves: XXXII Encontro Nacional De Engenharia De Produção, 2012.

BRIANT, A., COMBES, P. P. e LAFOURCADE, M. Dots to boxes: Do the size and shape of spatial units jeopardize economic estimations? Journal of Urban Economics, v. 67, i. 3, p. 287-302, maio 2010.

BRUCE, A. B. e CARRIQUIRY, M. An exploration of certain aspects of CARB's approach to modeling indirect land use from expanded biodiesel production. CARD Staff Report, Iowa, fev. 2010. Disponível em: $<$ www.cardiastate.edu >. Acesso em: 14 jun. 2011.

BRUM, A. L., DALFOVO, W. C. T. e AZUAGA, F. L. Alguns impactos da expansão da produção de soja no município de Sorriso-MT. Desenvolvimento em Questão, ano 7, n. 14, jul./dez. 2009. Disponível em: $<$ https://www.revistas.unijui.edu.br/index.php/ desenvolvimentoemquestao/article/view/177>.

CÂMARA, G. et al. Modelagem de mudanças de uso da terra no Brasil: 2000-2050. São José dos Campos, Brasília, Luxemburgo, Cambridge. INPE, IPEA, IIASA, UNEPWCMC, 2015.

CARVAlHO, A. X. Y., LAURETO, C. R. e PENA, M. G. Crescimento da produtividade agrícola nas microrregiões brasileiras. Texto para Discussão, n. 2099. Rio de Janeiro: IPEA, 2015. 62p. Disponível em: $<$ http://www.ipea.gov.br/portal/index.php?option $=$ com_content\&view $=$ article\&id $=25708>$.

CROCCO, M. A. et al. Metodologia de identificação de aglomerações produtivas locais. Nova Economia, Belo Horizonte, v. 16, n. 2, p. 211241, maio/ago. 2006. Disponível em: <http:// www.scielo.br/scielo.php?script $=$ sci_arttext\&pi $\mathrm{d}=$ S0103-63512006000200001>.

DALMÁs, S. R. S., STADUTO, J. A. R. e WILLERS, E. M. A identificação e cluster na atividade de abate de frangos na mesorregião Oeste do Paraná. Londrina: XLV Congresso da Sociedade Brasileira de Economia, Administração e Sociologia Rural, 2007.

DEVEREUX, M. P., GRIFFITH, R. e SIMPSON, H. The geographic distribution of production activity in the UK. Regional Science and Urban Economics, v. 34, n. 5, p. 533-564, 2004.

ESPIRITO SANTO, B. R. do, LIMA, M. L. F. N. de e SOUZA, C. B. S. de. Os vinte principais mercados para exportação agrícola no futuro. Revista de Política Agrícola, ano XXI, n. 1, p. 76-91, jan./mar. 2012. Disponível em: <https://www.embrapa.br/busca-de-publicacoes/-/ publicacao/930819/os-vinte-principais-mercados-paraexportacao-agricola-no-futuro $>$.

FERNANDES, K. C. C. et al. O Complexo agroindustrial da soja e a produção de biodiesel no estado de Goiás. Conjuntura Econômica Goiana, n. 23, dez. 2012. Disponível em: <http://www.imb.go.gov.br/pub/conj/ conj23/artigo05.pdf $>$.

FERREIRA, M. D. P. e COELHO, A. B. Desmatamento recente nos Estados da Amazônia Legal: uma análise da contribuição dos preços agrícolas e das políticas 
governamentais. Revista de Economia e Sociologia Rural, v. 53, n. 1, p. 93-108, jan./mar. 2015. Disponível em: <http://www.scielo.br/scielo.php?script=sci_arttext\& pid $=$ S0103-20032015000100091>.

FREITAS, R. E. Exportações agropecuárias brasileiras: uma avaliação do período 1989-2012. Texto para Discussão, n. 1964. Brasília: IPEA, 2014. 42p.

e ALVES, P. F. Prestação de serviços à agropecuária: perfil e distribuição. In: DE NEGRI, J. A. e KUBOTA, L. C. (Orgs.). Estrutura e dinâmica do setor de serviços no Brasil. Brasília: IPEA, v. 1, p. 377-407, 2006. Disponível em: < http:/www.ipea.gov.br/portal/images/ stories/PDFs/livros/capitulo_11_agricultura.pdf $>$.

MENDONÇA, M. A. A. e LOPES, G. O. Expansão de área agrícola nas mesorregiões brasileiras. Revista de Política Agrícola, ano XX, p. 100-116, jan./mar. 2011. Disponível em: <https://seer.sede.embrapa.br/ index.php/RPA/article/view/47/36>.

GASQUES, J. G., BOTELHO, F. e BASTOS, E. T. Preço de terras e sua valorização. Brasília: Mapa/AGE, versão preliminar, 2015, $8 \mathrm{p}$.

HADDAD, P. R. Medidas de localização e de especialização. In: HADDAD, P. R.et al.(Orgs.). Economia regional: teorias e métodos de análise. Fortaleza: BNBETENE, 1989. 694p.

HELFAND, S. M. e LEVINE, E. S. Farm size and the determinants of productive efficiency in the Brazilian Center-West. Agricultural Economics, v. 31, p. 241-249, 2004.

. MOREIRA, A. R. B. e FIGUEIREDO, A. M. R. Explicando as diferenças de pobreza entre produtores agrícolas no Brasil: simulações contra factuais com o Censo Agropecuário 199596. Revista de Economia e Sociologia Rural, v. 49, n. 2, p. 391-418, abr./jun. 2011. Disponível em: <http:// www.scielo.br/scielo.php?script $=$ sci_arttext $\&$ pi $\mathrm{d}=$ S0103-20032011000200006>.

IBGE - Instituto Brasileiro de Geografia e Estatística. Produção Agrícola Municipal (PAM). Rio de Janeiro, 2015. Disponível em: <http://www.sidra.ibge.gov.br/>. Acesso: 30 jul. 2015.

ISARD, W. Methods of regional analisys. Cambridge, Massachusets: The MIT Press, 1960. 784p.

ISSERMAN, A. The Location Quotient Approach to Estimating Regional Economic Impacts. Journal of the American Planning Association, v. 43, n. 1, p. 33-41, 1977.

KRUGMAN, P. Geography and trade. Cambridge: MIT Press, 1991. 156p.
LEITE, S. P. e WESZ Jr., V. Modèle de développement et dynamiques foncières au Brésil: analyse de l'expansion de l'agribusiness du soja et ses effets sur le millieu rural. Montpellier: CIRAD, 2010 (mimeo).

LU, Z., FLEGG, A. T. e DENG, X. Regional specialization: a measure method and the trends in China. MPRA Paper No. 33867, nov. 2011. Disponível em: <http:// mpra.ub.uni-muenchen.de/33867/>. Acesso: 30 ago. 2015.

MINGOTI, S. A. Análise de dados através de métodos de estatística multivariada - Uma abordagem aplicada. Belo Horizonte: Editora UFMG, 2005. 297p.

NAVES, I. M. Agronegócio e logística: dicotomia, 2009. Disponível em: < http://www.conab.gov.br/OlalaCMS/ uploads/arquivos/82db7583bb8bc046abd53e1545 9ec277.pdf>. Acesso: 19 abr. 2016.

PEREIRA, J. C. R. Análise de dados qualitativos. São Paulo: FAPESP, 2001, 157p.

PINTO; L. F. G. e SPAROVEK, G. A funcionalidade da agropecuária brasileira (1975 a 2020) the functionality of brazilian agriculture (1975 to 2020). Sustentabilidade em Debate, n. 2, dez. 2015.

REVEIU, A. E. e DARDALA, M. Quantitative Methods for Identification of Regional Clusters in Romania. Journal of Applied Quantative Methods, v. 6, n. 2, p. 1-11, summer 2011.

REZENDE,A.C.eDINIZ,B.P.C.Identificação declusters industriais: uma aplicação de índices de especialização e concentração, e algumas considerações. REDES - Rev. Des. Regional, Santa Cruz do Sul, v. 18, n. 2, p. 38-54, mai./ago. 2013. Disponível em: <https://online.unisc. br/seer/index.php/redes/article/view/1507>.

RUAN, J. e ZHANG, X. "Flying geese" in China: The textile and apparel industry's pattern of migration. Journal of Asian Economics, v. 34, p. 79-91, 2014.

SAS Business Intelligence software. Introduction to Clustering Procedures. The Number of Clusters, 2015a. Disponível em: <http://support.sas.com/ onlinedoc/913/getDoc/pt/statug.hlp/introclus_sect10. htm >. Acesso em: fev. 2015.

. The Cluster Procedure, 2015b. Disponível em: $<$ http://support.sas.com/onlinedoc/913/getDoc/pt/ statug.hlp/cluster_index.htm>. Acesso em: fev. 2015.

The Cluster Procedure. Example 23.3: Cluster Analysis of Fisher Iris Data, 2015c. Disponível em: <http://support.sas.com/onlinedoc/913/getDoc/pt/ statug.hlp/cluster_sect26.htm $>$. Acesso em: fev. 2015. 
SAUER, S. e LEITE, S. P. Expansão agrícola, preços e apropriação de terra por estrangeiros no Brasil. Revista de Economia e Sociologia Rural, v. 50, n. 3, p. 503-524, jul./set. 2012. Disponível em: <http:// www.scielo.br/scielo.php?script $=$ sci_arttext $\&$ pi $\mathrm{d}=$ S0103-20032012000300007>.

SOUZA, R. S. et al. Competividade dos principais produtos agropecuários do Brasil (vantagem comparativa revelada normalizada). Revista de Política Agrícola, ano XXI, n. 2, p. 64-71, abr.jun. 2012.

SPAROVEK, G. et al. Sustainable bioproducts in Brazil: Disputes and agreements on a common ground agenda for agriculture and nature protection. Biofuels Bioproducts and Biorefining, mar. 2016.

SUZIGAN, W. et al. Coeficientes de Gini Locacionais GL: aplicação à indústria de calçados do Estado de São Paulo. Nova Economia, v. 13, n. 2, p. 39-60, jul./dez. 2003.
Disponível em: <http://revistas.face.ufmg.br/index. php/novaeconomia/article/view/415>.

UNITED NATIONS (UN). World Population Prospects: The 2012 Revision, 2013. Disponível em: < http://esa. un.org/unpd/wpp/Excel-Data/population.htm $>$. Total Population - Both Sexes. Acesso: 14 abr. 2015.

VAN DEN HEUVEL, F. P., DE LANGEN, P. W. e FRANSOO, J. Spatial concentration and location dynamics in logistics: The case of a Dutch province. Journal of Transport Geography, v. 28, p. 39-48, jan. 2011. - et al. Identification of Employment Concentration Areas. European Planning Studies, v. 22, i. 1, p. 204-226, 2014.

ZITTA, M. et al. Territorial concentration and evolution of science and technology activities in the European Union: a descriptive analysis. Research Policy, v. 28, i. 5, p. 545-562, jun. 1999. 
